\title{
EMBOLIA GORDUROSA CEREBRAL PÓS-TRAUMÁTICA
}

\author{
Darcy de Freitas Vellutini * \\ SHINICHI IsHIOKA ** \\ Lamartine CORReia de Morais JR. ***
}

\begin{abstract}
A embolia gordurosa é uma das mais importantes causas de mortalidade em pacientes com fraturas. Embora a patogenia seja controvertida e ainda não haja tratamento preventivo eficaz, o diagnóstico pode ser feito com segurança. De acôrdo com Peltier ${ }^{7}$, a embolia gordurosa nos capilares do pulmão foi primeiramente descrita por Zenker em 1862 e sua patologia delineada por Wagner em 1865; sòmente em 1873 foi que Bergmann fez o primeiro diagnóstico clínico.
\end{abstract}

O presente trabalho registra dois casos de embolia gordurosa ocorridos em pacientes politraumatizados.

\section{O B S E R V C O E S}

Caso 1 - I.M. com 33 anos de idade, sexo masculino, internado no Pronto Socorro do Hospital das Clínicas da Universidade de São Paulo (reg. 142368) em 18-5-1968, vitima de acidente automobilistico. Ao exame, o paciente se apresentava consciente, bem orientado no tempo e no espaço. Escoriaçōes no rosto. Pressāo arterial $155 \times 80$; Pulso 88; Temperatura $36^{\circ} \mathrm{C}$. Esmagamento da perna esquerda e fratura completa do $1 / 3$ médio do femur; fratura exposta do $1 / 3$ distal da tíbia e perônio à direita. Foi felta, sob anestesia geral, limpeza cirúrgica da fratura no membro inferior direito e amputaçāo do membro inferior esquerdo ao nivel da coxa. No dia seguinte o paciente mostrou-se torporoso, confuso, sem rigidez de nuca e sem sinais neurológicos focais. Com a suspeita de embolia gordurosa, foram pedidos exames complementares. Liquido cefalorraqueano normal. Pesquisa de goticulas de gordura na urina positiva. Taxa de lípides totais $385 \mathrm{mg} / 100 \mathrm{ml}$. Uréia no sangue $54 \mathrm{mh} / 100 \mathrm{ml}$. Hemograma: 3.600.000 glóbulos vermelhos; Hemoglobina 11,1 gr/100 $\mathrm{ml}(69 \%)$. No 4.0 dia apareceram petéquias distribuidas pelo tórax e pescoço que desapareceram ao fim de três dias. O tratamento consistiu na administração de sangue total, manitol a $20 \%$, dexametasona, álcool absoluto diluído em sôro glicosado a $5 \%$ e antibióticos. Houve melhora progressiva do estado de consciêncla, com recuperação total da parte neurológica, sendo dada alta em 30-5-1968.

Caso 2 - J.M.A.M. com 21 anos de idade, sexo masculino, internado no Hospital da Beneficência Portuguêsa de Sāo Paulo (Reg. 155203) em 2-9-1968, vítima de acidente automobilístico. O paciente se apresentava torporoso, sem rigidez de nuca e sem sinais neurológicos focais. Pressão arterial $120 \times 80 ;$ Pulso 120 ; Afebril. Fratura do femur à direita e de tíbia à esquerda. Após 13 horas de internação, o

Departamentos de Neurologia e de Cirurgia da Faculdade de Medicina da Universidade de Sāo Paulo: * Neurocirurgião; ** Cirurgião geral; *** Médico estagiário. 
paciente apresentou hipertermia e crises convulsivas generalizadas. A carotidoangiografia foi normal, tendo sido entāo levantada a hipótese de embolia gordurosa. Dos Exames realizados, a pesquisa de gordura na urina foi poitiva e o hematócrito foi de $27 \%$. Com o aparecimento de secreção brônquica abundante foi feita traqueostomia. No $4 .^{\circ}$ dia apareceram petéquias disseminadas pelo tórax e pescoço. O tratamento consistiu na administração de sangue total, manitol a $20 \%$, corticóides, álcool absoluto diluido em sôro glicosado a $5 \%$ e antibióticos. Houve piora progressiva no quadro clínico, ocorrendo o óbito em 8-9-1968.

$\mathrm{Na}$ etiologia da embolia gordurosa as particulas embolizantes podem partir do sistema ósseo (fraturas de ossos longos, operações ortopédicas) da gordura subcutânea e intermuscular e da gordura visceral. Embora o quadro clínico da embolia gordurosa não seja muito freqüente, as necrópsias de pacientes traumatizados mostram sua alta incidência (Denman e Gragg ${ }^{1}$, Emson ${ }^{2}$, Kuhne e Kremser ${ }^{4}$, Takats e col. ${ }^{12}$ ). De 66 casos revistos na literatura por Moine e Lagrave ${ }^{6}$, ocorreu o óbito em 32 . Inicialmente ocorre um quadro pulmonar (embolia gordurosa pulmonar) e, ulteriormente, surgem indícios de embolia gordurosa sistêmica que ocorre seja devido à persistência do foramen oval ou através dos capilares pulmonares para as veias pulmonares.

A embolia gordurosa pulmonar é definida por Vance ${ }^{13}$ como uma obstrução na circulação pulmonar com acentuada queda nas trocas respiratórias dos alvéolos. Seus sintomas são: tosse, dor torácica, dispnéia, cianose, estertores, escarro sangüinolento e hipertermia. O aparecimento, na radiografia de tórax, de imagem miliar macronodular nas duas bases, segundo Lavarde ${ }^{\overline{5}}$, confirma o diagnóstico. A pesquisa de gotículas de gordura no escarro tem valor diagnóstico duvidoso, pois admite-se poder ser ela normalmente ali encontrada. Insuficiência cardíaca direita pode ser secundária à hipertensão na artéria pulmonar. Os achados eletrocardiográficos que, segundo Peltier ${ }^{7}$, podem ser encontrados são: taquicardia, aparecimento súbito de ondas $\mathrm{S}$ profundas em D1 e ondas $Q$ profundas em D3, e o desvio da zona de transição para a esquerda. Arritmias são freqüentes. Existe inversão da onda T, provàvelmente indicando severa sobrecarga do ventrículo direito. Depressão do segmento ST também ocorre por isquemia subendocárdica; pode haver bloqueio do ramo direito. Nos nossos casos o quadro pulmonar foi evidente apenas em um dêles (caso 2).

Vencida a barreira pulmonar que atua como filtro para as gotículas de gordura, ocorre embolia gordurosa sistêmica. Kuhne e Kremser ${ }^{4}$ verificaram, na autópsia de 643 traumatizados, que $95 \%$ dos pacientes tinham tido embolia pulmonar, ao passo que sòmente $23 \%$ tiveram embolia gordurosa sistêmica. Nesta, as gotículas de gordura se distribuem a todos os órgãos, causando maiores danos no encéfalo, no coração e nos rins. Ao exame anátomo-patológico, o encéfalo mostra petéquias múltiplas e difusas, principalmente na substância branca. 
A sintomatologia decorrente das lesões cerebrais pode simular e existência de hematoma intracraniano pois também ocorre o chamado "intervalo livre" entre o traumatismo e o aparecimento dos sintomas; isto ocorre em $85 \%$ dos casos, segundo Sachdeva e col. ${ }^{8}$, dentro das primeiras 48 horas, com sintomas traduzidos por alteração da consciência sem sinais neurológicos focais. $O$ intervalo livre esteve presente apenas no caso 1 , aqui relatado.

As petéquias hemorrágicas são consideradas como patognomônicas de embolia gordurosa sistêmica decorrente da embolia gordurosa das arteriolas do derma; elas se localizam no pescoço, ombros, tórax e, raramente, na parede abdominal; podem ser encontradas no pálato mole e na subconjuntiva; podem aparecer precocemente no $2 .^{\circ}$ ou $3 .^{\circ}$ dia, com duração média de 48 horas. Peltier ${ }^{7}$ assinalou petéquias em $20 \%$ de seus casos; Hirsch e col. ${ }^{3}$ relataram 30\%. Elas estiveram presentes nos nossos casos e seu aparecimento se deu no $4 .^{\circ}$ dia.

Os rins, mesmo nos casos graves, não apresentam lesões severas; o aparecimento de lipúria, segundo Vance ${ }^{13}$, se dá ou por filtração dentro da cápsula de Bowman através da parede intacta do vaso ou por rotura dos glomérulos. Usando método microscópico para pesquisar goticulas de gordura, Peltier ${ }^{7}$ obteve, em 40 pacientes traumatizados, um teste positivo em $57 \%$ dos casos. A sua pesquisa foi positiva nos nossos 2 casos.

Diminuição no valor da taxa de hemoglobina tem sido apontada como elemento valioso para o diagnóstico de embolia gordurosa. Esta queda se dá mesmo nos casos em que se fêz a reposição do sangue perdido no momento do traumatismo, sendo devida à hemorragia pulmonar. Nos nossos casos, constatamos uma queda na taxa de hemoglobina que foi bem maior no caso 2 .

A lipase do sôro se apresenta elevada sòmente 3 a 4 dias após o traumatismo, permanecendo elevada até o $7^{\circ}$ ou $8^{\circ}$ dia. Segundo Peltier ${ }^{7}$ e Sanchdeva e col. ${ }^{4}$, a determinação da lipase no sôro é o melhor exame complementar para fins de diagnóstico, devendo ser feito entre o $3 .^{\circ}$ e o $7 .^{\circ}$ dia após o traumatismo.

O exame do líquido cefalorraqueano é normal, não sendo nêle encontradas gotículas de gordura; o eletrencefalograma pode mostrar-se alterado sem caráter específico.

O tratamento da embolia gordurosa engloba vários aspectos. Trabalhos experimentais de Soloway e col. ${ }^{11}$ mostraram que o animal hipovolêmico retém, no parênquima pulmonar, $19 \%$ de gordura mais que o animal normotenso; daí a necessidade da correção da anemia que o paciente possa apresentar, mediante transfusões de sangue total. O tratamento da complicação pulmonar se faz pela traqueostomia, administração de oxigênio e, nos casos mais graves, com respiração controlada por aparelhos tipo Bird. O uso de álcool absoluto e de heparina, indicados por alguns autores (Hirsch e col. ${ }^{3}$, Moine ${ }^{6}$, Soloway ${ }^{11}$ ) tem dado lugar a controvérsias. Em trabalhos experimentais, Sachdeva e col. ${ }^{10}$ usaram o ACTH e Fenergan pelas suas propriedades anti-histamínicas e anti-inflamatórias, acreditando ser a anóxia devida ao bloqueio mecânico da circulação pulmonar causado pelos glóbulos de gor- 
dura e também por substâncias semelhantes à histamina que são liberadas localmente no tecido lesado, sendo responsáveis pelo bronco e vasoespasmo. Nos nossos casos, apesar de realizarmos um tratamento padronizado, que consistiu em sangue total, manitol, álcool absoluto diluído em sôro glicosado, corticóide e antibióticos, obtivemos bom resultado em apenas um. Isto se deve, provàvelmente, ao grau de intensidade da embolia gordurosa sistêmica existente.

R E S U M O

São relatados dois casos de embolia gordurosa pós-traumática, sendo estudados os sinais e sintomas que caracterizam sua forma pulmonar e sistêmica e relatados os métodos paraclínicos utilizados na confirmação do diagnóstico, tais como radiografias de tórax, eletrocardiograma, hemograma, dosagem de lipase no sôro e pesquisa de gordura no escarro e na urina. São comentados os diversos tipos de tratamento empregados.

\section{S U M M A R Y}

\section{Cerebral post-traumatic fat embolism: report of two cases.}

Two cases of post-traumatic fat embolism are reported. The pulmonary and systemic signs and symptoms are analysed. The paraclinical methods for diagnosis such as chest roentgenograms, electrocardiogram, hemoglobin and serum lipase values and the finding of fat droplets in sputum or in urine are emphazised. The basis for treatment are discussed.

\section{REFER E C I A S}

1. DENMAN, F. R. \& GRAGG, L. - Fat embolism. A diagnosis enigma. Arch. Surg., $57: 325,1948$.

2. EMSON, H. E. - Fat embolism studied in 100 patients dying after injury. J. clin. Path., 11:28, 1958.

3. HIRSCH, J. R.; KINIFFO, H. V. \& LEVANE, J. H. - L'embolie graisseuse posttraumatique. J. Chir., 93:99, 1967.

4. KUHNE, H. \& KREMSER, K. H. - Die klinische Bedeutung der traumatischen Fettembolie. Brum's Beitr. Z. Klin. Chir., 195:385, 1957.

5. LAVARDE, G. - Un cas d'embolie graisseuse post-traumatique guérie par la ventilation artificlelle continue. Mem.Acad. Chir., 93:423, 1967.

6. MOINE, M. \& LAGRAVE, G. - Les problèmes diagnostique et therapeutiques posés par l'embolie graísseuse. Mem. Acad. Chir., 93:567, 1967.

7. PELTIER, L. F. - The diagnosis of fat embolism. Surg. Gynec. Obst., 121: 371, 1965.

8. SACHDEVA, V. P.; SACHDEVA, H. S.; GUlati, D. R.; MALlikaRJUM, T. S. \& GREWAL, D. S. - Sistemic fat embolism: review of literature and a report of three cases. Amer. Surg., 35:369, 1969.

9. SACHDEVA, H. S; HALlikaRJUM, T. S.; CHAKRAVATI, R. N. \& ANANA, S. S. - Fat embolism: an experimental study (Part I). Amer. Surg., 35:250, 1969. 
462 ARQ. NEURO-PSIQUIAT. (SÄO PAULO) VOL. 29, N.० 4, DEZEMBRO, 1971

10. SACHDEVA, H. S.; SACHDEVA, K. C. \& CHAKRAVATI, R. N. - Fat embolism. An experimental study: evaluation of smooth muscle relaxants in treatment. Amer. Surg., 35:257, 1969.

11. SOlOWAY, H. B.; ROBINSON, E. F.; HERFUAZEL, H. V. \& HUYSER, K. L. Experimental fat embolism. Initial distribution of fat embolism labeled with $I^{131}$ in normotensive and hypotensive rabbits. Arch. Path., 88:171, 1969.

12. TAKATS, G.; BECK, W. G. \& FENN, K. F. - Pulmonary embolism. Surgery, $6: 339,1939$.

13. VANCE, B. M. - The significance of fat embolism. Arch. Surg., 23:426, 1931.

Clinica Neurológica - Faculdade de Medicina da Universidade de São Paulo - Caixa Postal 3461 - São Paulo, SP. - Brasil. 